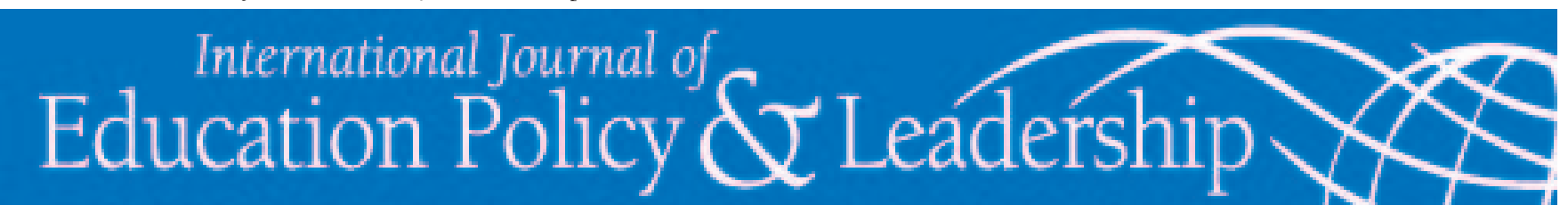

\title{
Impacts of School Organizational Restructuring into a Collaborative SetTing on the NATURe of EMERging Forms of Collegiality
}

\author{
GERALD FALLON \\ The University of Saskatchewan \\ JOHN BARNETT \\ The University of Western Ontario
}

\begin{abstract}
This case study tells the story of an elementary school staff on the west coast of Canada that decided to address their perceived problem of teacher isolation by transforming the internal organization of their school into a collaborative environment designed to foster collegial practices among themselves. The main guiding question of this study was: can a collaborative organizational structure facilitate and sustain a level of collegiality in which people feel safe from attack, where difficult questions are addressed, and where the status quo can be safely challenged? In this study, the transformation of organizational structure of the school elicited and molded, to an extent, the professional behaviours of members of the staff into professional collegial patterns of interactions. However, we have found that educators seemed to have made individual choices to maintain a certain degree of isolation, of privacy, shielding themselves from reflective inquiry and criticism.
\end{abstract}

Fallon, G., Barnett, J. (2009). Impacts of School Organizational Restructuring Into a Collaborative Setting on the Nature of Emerging Forms of Collegiality. International Journal of Education Policy and Leadership 4(9). Retrieved [DATE] from http://www.ijepl.org.

\section{Introduction}

A significant number of teachers spend nearly all their time with students or alone planning and grading papers, it is not surprising to hear them say that they feel isolated from their colleagues (Lortie, 1975; Rosenholtz, 1989). According to some scholars (Deaudelin, Dussault, \& Thibodeau, 2003; Flinder, 1988; Smith \& Scott, 1990), the perception that teaching is an isolated and self-reliant profession is partly the result of the nature of the school's internal organizational structure. As a result, more and more schools are trying to break this perception of professional isolation among teachers by creating and implementing organizational structures designed to foster collegiality (Fullan, 1991; Hoy \& Sweetland, 2001; Johnson, 1998).
This article tells the story of the staff of an elementary school on the west coast of Canada that addressed their perceived problem of teacher isolation by attempting to transform the school's internal organization into a more collaborative environment designed to foster collegial practices. The main guiding question of our study was this: Can a collaborative organizational structure facilitate and sustain a level of collegiality in which people feel safe from attack, supported, and emotionally secure, and in which difficult questions are addressed, risk taking is valued, and the status quo can be safely challenged? There have been few reports of schools in which staff members have deliberately chosen to transform the organizational structure of their school by fostering collegial interactions as means of minimizing per- 
ceived teacher professional isolation. In effect, then, our study offers a unique contribution to the literature.

The purpose of the study was threefold: (1) to describe the concept of collaborative school organizational structures and the notion of collegial practices while exploring the theory and research that link those two constructs; (2) to study and describe the dynamics of collaborative school structure in terms of providing possibilities for emerging collegial practices; and (3) to discuss the practical and theoretical implications of this case study while suggesting future research directions.

\section{Context of the Study}

We conducted the study in a French immersion school of approximately three hundred students in a medium sized city in British Columbia, Canada. The school was of particular interest because it is considered a flagship in the school district due to its high student achievement scores and strong parental support and involvement. The school's culture was such that staff and parents considered high student achievement the only indicator of school quality. Teachers and school administrators were working in an environment of increasing demands for better student achievement. Administrators and teachers had a strong interest in maintaining school legitimacy through a conventional and assembly-line type of organizational school structure. On the surface, there was no reason to change. However, there was a strong sense of professional isolation among staff, which called into question the school's internal organizational structure.

In late June 2006, and again in August of that year the study was done, staff members engaged in group reflection about their sense of professional isolation and ways to minimize these feelings. Their reflection led them to embark on an organizational restructuring of the school to create space and time for increased professional and personal interactions related to issues of teaching and educational planning. Central to the process was the design and implementation of a master schedule that incorporated team-teaching options such as grade-level teaching teams, staff development opportunities that featured daily common planning time for all teachers, a collaborative decision-making process that invited teacher input through participation in school improvement committees focusing on issues of teaching practices and planning, and a learner-centered professional development philosophy that placed a greater emphasis on collaborative group work. The staff perceived their school's more collaborative environment as central to overcoming their professional isolation. Thus, the school was already well on its way to becoming a collaborative and, perhaps, collegial entity because teachers wanted to create an organizational structure that supported connection rather than separation.

Although these educators were able to create some organizational conditions leading to the emergence of collegial practices, questions remained about the forms and content of the collegial practices that would be achieved and how they would affect professional boundaries. Also, given that the main intent of the organizational restructuring was overcoming isolation, the changes would affect the nature and extent of collegiality, leading us to question its determinants.

\section{Theoretical Framework}

In our attempt to grasp the notions of collaborative organizational structure and collegial practices in all their complexity, we became aware that we needed to build an overall conceptual framework. That framework needed to be one that most readers would, with careful thought, view as an adequate basis for in-depth analysis, one that could lead to useful insights into what drove the research participants to intentionally redesign the organizational structure of their school, their understanding of its meaning and functions, and their level of engagement in collegial practices.

The first step in constructing a coherent conceptual framework was to chart a clear position on the notion of collaborative organizational school structure and its dimensions, features, and functions. To complete our framework, we reviewed the literature addressing the concept of collegial practices and its relationship to internal dynamics of a collaborative organizational school structure intentionally designed to respond to perceived feelings of professional isolation. Together these components provided a conceptual foundation to guide our research.

\section{Collaborative Organizational School Structure: Meanings, Characteristics, and Functions}

Organizational structure can be defined as the way a school is patterned or arranged (Johnson, 1998), and the relational ways in which educators intentionally construct collaborative organizational provides the first "layer" in our conceptual framework. We define a collaborative organizational school structure as a socially constructed entity (Vygotsky, 1978; Lavié, 2006), an aggregate of diverse educators who express their motivations and shared experiences or interests; negotiate change and power sharing (power that derives from their knowl- 
edge, skills, and competencies) in coping with challenges (such as professional isolation); and plan and implement changes (Brint, 2001). We do not suggest that the concept of collaborative organizational school structure should be treated as an "idealized fantasy of commonbeing, nor a unity of experience or perspective" (Welch $\&$ Panelli, 2007, p. 350), nor as a relatively homogenous social category requiring sameness. Instead, we conceptualize a collaborative organizational school structure as a continually shifting, imprecise, porous, and malleable landscape of connection originating from one discourse or another about motives for collaborative interaction within an organizational structure (Brint, 2001; Irwin \& Farr, 2004; Lavié, 2006; McMillan, 1996; Welch \& Panelli, 2007).

These motives embedded in specific discourses dealing with teacher collaboration are centrally important in our understanding and conceptualization of collaborative organizational school structures. The primary motivators of particular interactions and connections among members of a school influence its collective organizational form (Zellermayer \& Margolin, 2005). Lavié (2006) differentiates among five complementary discourses that provide an understanding of the multisided phenomenon of collaborative organizational school structure in terms of its focus of attention (strategic purposes), the meaning it attaches to teacher collaboration, its purpose, and its value orientation (see Table 1).

This perspective casts collaborative organizational school structure as a complex, iterative, nonlinear process in which a group of educators structurally organize themselves following their driving forces (primary motivators expressed in specific kind of discourses, as shown in Table 1)_permitting, enabling, precipitating events, processes, and conditions that shake the community and place it at the edge of organizational restructuring (Levy \& Merry, 1986). Such specific discourses create "defining moments" (Grimmett, 2000) for potential redesign of a school organizational structure (Zellermayer, 2001) and situations in which individuals can no longer interact or participate in ways they once did (Matuzov \& Hayes, 2002).

We view this question of driving forces or discourses as critical in explaining human engagement in designing a specific collaborative organizational school structure that is relevant to its participants. The nature of these driving forces or discourses affects the characteristics of a collaborative organizational school structure, its internal functioning, and the types of emerging collegial interactions (Lavié, 2006; Zellermayer \& Margolin, 2005). As highlighted by some authors (Graham, 2001;

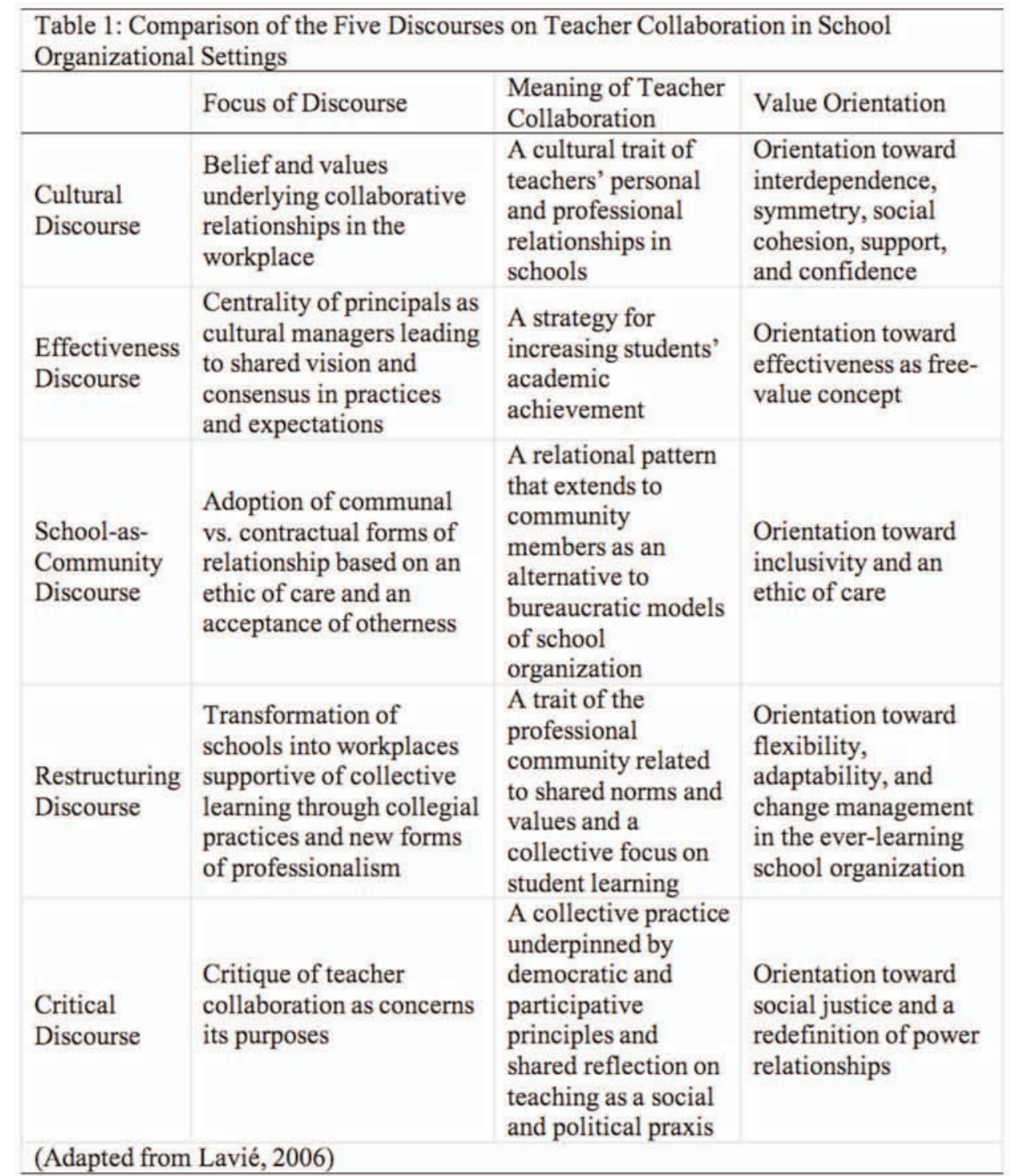


Hoy \& Sweetland, 2001; Marks \& Louis, 1999; Smith \& Scott, 1990; Tschannen-Moran, Uline, Woolfolk Hoy, \& Mackley, 2000), the various notions of collaborative school structures have been portrayed as having some specific generic characteristics. First, in terms of strategic purpose, such a model requires an organizational structure that fosters collaboration and interdependence among educators, as opposed to a structure in which teachers are not able to exercise influence and use their collective knowledge to discuss and resolve schoolwide issues. Second, a collaborative school structure involves a governance structure characterized by educators' sharing of an equal voice in a dynamic of power with nonhierarchical control, as opposed to a highly centralized decision-making structure designed to guarantee compliance. Third, a set of coordinating activities designed to increase and sustain collaboration and collegial patterns of interactions is needed, as opposed to balkanized activities residing in separate and noncommunicative subgroups. Fourth, in terms of practices and internal organizational structures, such a model needs to enable educators to generate knowledge by designing, planning, researching, evaluating, and preparing new ways of acting, teaching, and interacting, as opposed to unshared individually held knowledge that impedes the development of clear, commonly held sets of ideas and practices. Fifth, a safe environment needs to exist, in which educators can provide one another useful critiques of their teaching and make contributions to the school, as opposed to an environment that breeds disagreement and conflict that undermines school wide collective knowledge processing and decision making. Last, there is a definite need for a shared power arrangement in which the exercise of power is dispersed among staff and targeted at issues central to the common good as opposed to a consolidated exercise of power with the administration or a small group of people.

To represent the importance of these fundamental contextual dimensions in understanding the basis of forms of collaborative school organizational structures and the consequences arising from them in terms of types of learning and changes, we have shown in Figure 1 what does shape-often powerfully - the forms and functions of such an organizational structure.

In sum, the challenge of designing, implementing, and sustaining an effective collaborative school structure conducive to the emergence of collegial practices in
Figure 1: Collaborative Organizational School Structure: Meaning, Origins, Characteristics, and Functions

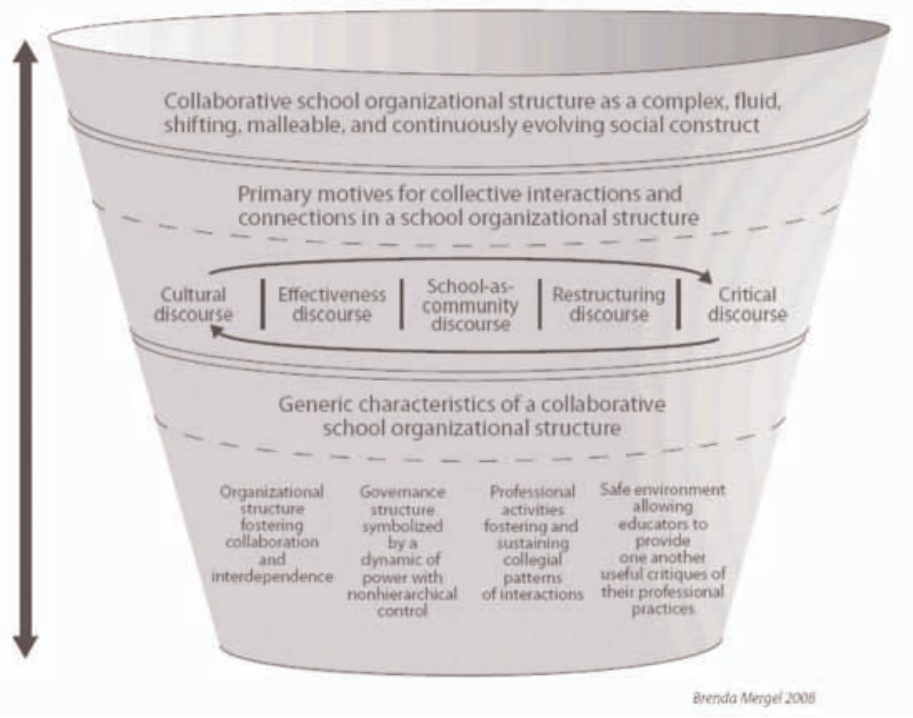

response to perceived professional isolation among staff is a daunting task. To say that collaborative schools are complex entities that defy easy generalization is an understatement.

\section{The Nature and Purposes of Collegiality}

The literature on collegiality provides the content and structure for the next layer in our conceptual framework. Several scholars treat collegiality as a multidimensional concept for which there can be no fixed definition (Barth, 1990; Fullan, 1991; Jarzabkowski, 2002; Little, 1990). Little (1990) identifies four different kinds of collegial work practices among teachers (see Table 2 on page 5). She describes the first three types of collegial practices-(1) storytelling and scanning, (2) aid and assistance, and (3) sharing-as weak forms of collegiality. She argues that limiting collegial work practices to anecdotes, giving help only when asked, or pooling existing ideas simply confirms and maintains the status quo. The fourth type, joint work, is the strongest form of collegiality. Joint work implies and creates stronger interdependence, shared responsibility, and a greater readiness to participate in reviewing and critiquing teaching practices and realities.

According to some scholars, the weak forms of collegiality dominate in schools (Campbell \& Southworth, 1992; Little, 1990). This phenomenon has led to the emergence of what Fullan and Hargreaves (1992) call a comfortable collegiality, which does not extend to class- 


\begin{tabular}{|c|c|c|}
\hline \multicolumn{3}{|c|}{ Table 2: Collegial Practices } \\
\hline & $\begin{array}{l}\text { Storytelling } \\
\text { and } \\
\text { scanning }\end{array}$ & $\begin{array}{l}\text { Under conditions of nearly complete independence, teachers } \\
\text { satisfy the demands of daily classroom life by occasional forays } \\
\text { in search of specific ideas, solutions, or reassurances. Contacts } \\
\text { between teachers are opportunistic and serve to reinforce a } \\
\text { culture of individualism and conservatism. }\end{array}$ \\
\hline $\begin{array}{l}\text { Weak } \\
\text { forms of } \\
\text { collegiality }\end{array}$ & $\begin{array}{l}\text { Aid and } \\
\text { assistance }\end{array}$ & $\begin{array}{l}\text { A second conception equates collegiality with the ready } \\
\text { availability of mutual aid. Teachers carefully preserve the } \\
\text { boundary between offering advice when asked and interfering } \\
\text { in unwarranted ways in another teacher's work. Contacts } \\
\text { between teachers serve to confirm present practices without } \\
\text { evaluating their worth. }\end{array}$ \\
\hline $\begin{array}{l}\text { Strong } \\
\text { form of } \\
\text { collegiality }\end{array}$ & Joint work & $\begin{array}{l}\text { This conception of collegiality highlights the routine materials } \\
\text { and methods or the open exchange and use of ideas and } \\
\text { opinions. Sharing varies in form and consequence. It may prove } \\
\text { normatively permissive or obligatory, may engage more or } \\
\text { fewer teachers, and may be fully reciprocal or only marginally } \\
\text { so. } \\
\text { Joint work is a process of co-participation that entails reflective } \\
\text { inquiry, criticism, and learning as integral constituents, as } \\
\text { opposed to acquiring or exchanging and accepting ideas, ready- } \\
\text { made materials, or tricks without inquiry or criticism. }\end{array}$ \\
\hline
\end{tabular}

room settings where educators might be involved in joint teaching, mutual observation of one another's work, or critical analysis of one another's practices. Tougher questions about one's practices and their underlying values or assumptions and how to improve them are kept off the agenda. This type of collegiality does not embrace the principle of systematic, reflective practice because it limits reflective approaches to procedural questions and ignores the propositional questions that could challenge the taken-for-granted ends toward which teaching is directed. These kinds of collegial practices emphasize reassurance and sympathy while discouraging close scrutiny and criticism. As Little (1990) points out, "such norms may provide teachers with collective permission for poor performance and marginal commitment" (p. 524). These superficial, weak, and comfortable kinds of collegiality lead to few, if any, significant improvements in instructional practices in the classroom (Fullan, 1991) and have little impact on the school culture in terms of continuous renewal (Fullan, 1991; Little, 1990; Sergiovanni, 1990). They lead to changes that improve the efficiency and effectiveness of what is currently done, without disturbing basic organizational features. This weak collegiality, although comfortable, places too much emphasis on sharing and celebrating experience and not enough on inquiring into principles, assumptions, and practices of teaching.

Joint work-the strongest form of collegial practice (e.g., team teaching, planning, inquiry, observation, action research, peer coaching, and mentoring) implies collective action, stronger interdependence, shared responsibility, and a greater readiness to participate in reflective inquiry (examining practices critically, seeking better alternatives, and assessing the worth of alternatives). This is a mode of coparticipation that entails reflective inquiry, criticism, and learning as integral constituents, as opposed to the simple acquisition and acceptance of ideas, ready-made materials, and tricks without inquiry or criticism. Failure and uncertainty are not hidden or defended; rather, they are shared and discussed. This kind of strong collegiality is most likely to lead to significant improvement and change (Barth, 1990; Fullan, 1993; Little, 1990). All in all, scholars (Fullan, 1991; Little, 1982, 1990) recognize the merit of a reflective stance toward teaching if it is construed in a way that permits and requires broader questions to be asked about what is worthwhile in teaching and why it is important. Figure 2 presents our representation of the levels of collegial practices that might emerge within a collaborative organizational school structure.

Figure 3 presents the overall conceptual framework we used to develop an understanding of how research

Figure 2: Levels of Collegial Practices

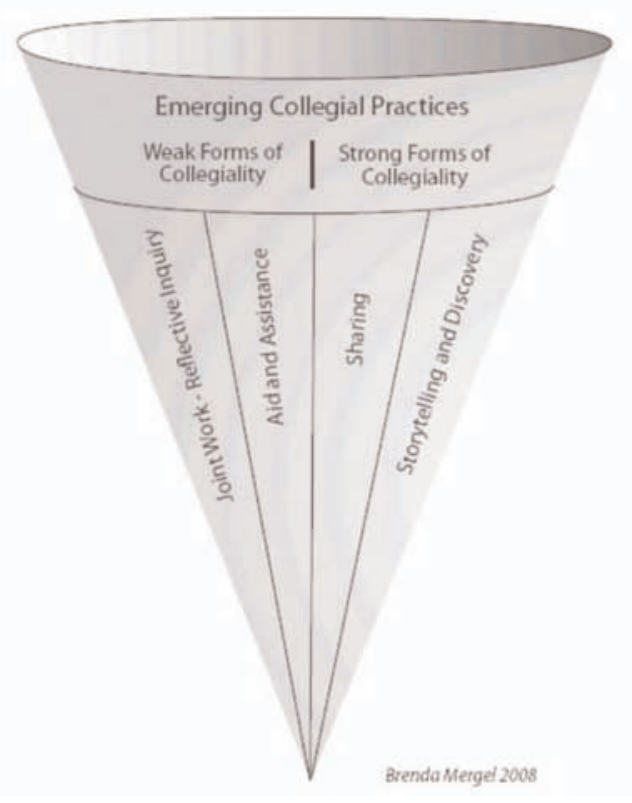


participants in the school we studied intentionally redesigned their organizational school structure, and the kind of collegial practices they have engaged in as a result of their restructured working environment. Our

\section{Figure 3: Overall Conceptual Framework}

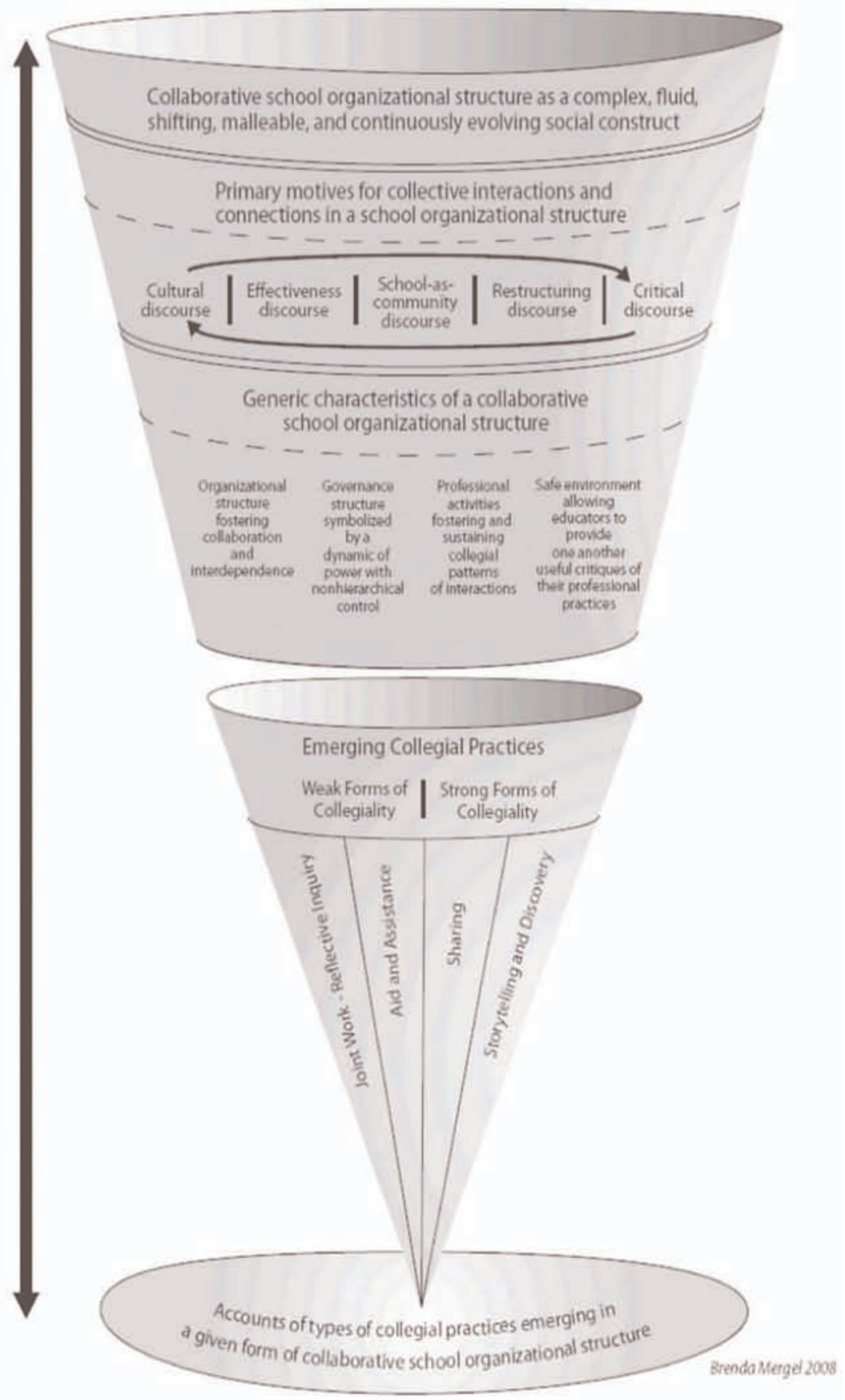

development of professional organized settings over time within a school. Both focus on professional and organizational activities as the site where teaching and administrative staff negotiate meaning and where a school organization develops, reifies, and transforms common professional practices and organizational structures. Our conceptual framework also promotes a view of organizational structure and context that intertwines physical surroundings, organized spaces, professional relationships, and the meaning that teachers and school administrators attribute to the professional actions they perform within their school.

\section{Methodology and Procedures}

The main purpose of our study was to develop an understanding of how and to what extent intentionally restructuring a school's organization in response to teachers' sense of professional isolation can support the emergence of collegial interactions. The study embodied the characteristics of exploratory, explanatory, and descriptive case study research. Based on Robson's (1993) and Yin's (1993) classifications, the study was exploratory because it sought to:

- Develop a comprehensive understanding of the events leading up to the redesign of the school's organizational structure into a collaborative one conducive to the emergence of collegial practices.

- Understand the ways that collaborative organizational school structure was understood and put into action by those who had firsthand experience with its design and implementation in their school.

- Develop insight into the contextual influences that shaped the design and implementation of the process.

The study was explanatory because it sought to:

- Understand how the meanings

conceptual framework illustrates that the concepts of collaborative organizational school structure and collegial practices are complementary, since they share basic premises about professional activity, meanings, and the ascribed to the notion of collaborative school structure by the research participants influenced the participants' engagement in terms of the types of collegial practices. 
- Learn what perceived level of collegial practices was achieved and understand the reasons why collegial practices among research participants looked the way they did.

The exploratory and explanatory nature of the study was complemented by a descriptive element that sought to:

- Provide an accurate profile of events and situations that occurred during the course of school organizational restructuring into a collaborative one.

- Identify key core beliefs and ideas that shaped the organizational school structure.

Because this study aimed to understand the complex nature of redesigning a school's organizational structure into a collaborative one conducive to the emergence of collegial practices, our intention was to emphasize the personal perspectives of those experiencing the voluntary design process. We also wanted to establish how the perceived impact of the organizational redesign affected the sustained collegial practices that emerged over the period of the study.

Given these goals and the context in which we were working, we used a case study approach (Mirriam, 1998; Yin, 2003) because it provided a methodology that enabled us to conduct an in-depth, multifaceted inquiry of a single phenomenon using several procedures and data sources (archival school data, internal policy school documents, and semistructured interviews). According to Yin (2003), case study methodology is most useful when the phenomenon under study is not readily distinguishable from its context.

In our case, teachers interacting within structured patterns of collegiality were social entities responsive and connected to the larger organizational environment of a school. Case study was also appropriate because the process occurred during a specific time frame that was easily bounded. The process itself was important to study because teachers' perceived isolation had never before been linked to voluntary organizational restructuring. The developments undertaken by the staff at this school made a strategic case for our investigation into the linkages between voluntary organizational restructuring, emergent collegial practices, and teachers' perceived isolation.

\section{Data Collection and Analysis}

At the time of the study, 21 full-time teachers were employed; of these, 18 (including the school administrator) agreed to participate in the study. Female staff members at the school outnumbered their male counterparts at a ratio of 3:1. Staff members' ages ranged from 26 to
60. Staff turnover was low, with a mean length of service of 9 years. The principal had 13 years of experience as a teacher and a further 6 years as an elementary school principal.

We collected data for this study from 18 face-to-face semistructured audio-recorded interviews with the educators, observation of 5 group meetings (one every two months) and 10 grade-level teaching team meetings (one per month) over the course of one academic year, and school documents.

Each semistructured interview lasted between 30 and 45 minutes; we used the questions as guides to conversation rather than as an oral survey (Miles $\&$ Huberman, 1994). During the interviews, we asked the participants to respond to open-ended questions about how they understood the nature and sources of their perceived professional isolation, how and why they came to make the decision to restructure their school, and the nature and content of collegial interactions they had with colleagues during staff and grade-level teaching team meetings. We also asked participants to describe to what extent those organizational factors that seemed to facilitate collegial patterns of interactions worked. Finally, we collected official documents including the school mission and vision statement, the organizational structure chart, ground rules of the grade-level teaching teams, meeting agendas, and minutes of staff meetings.

We organized, classified, and coded data from the transcribed audio-taped interviews and field notes taken during staff and grade-level teaching meetings in accordance with the principle of inductive research and comparative analysis (Creswell, 1998; Glaser, 1967). This procedure allowed us to progressively and inductively develop themes and conceptual constructs (Mirriam, 1998). We did our initial coding using a priori codes derived from the literature on collegial patterns of interactions and collaborative school organizational structure (see Table 3 on page 8). We included a few additional codes that emerged as the data required (Lincoln $\&$ Guba, 1985).

To ensure the accuracy of the findings, we sent the interview transcripts and our interpretations to research participants for member checking (Lincoln \& Guba, 1985). Furthermore, we addressed any problems of trustworthiness in the data by using multiple sources of data to triangulate multiple indicators of the same phenomenon (Creswell, 1998; Denzin \& Lincoln, 2000). As a result, we made some factual corrections and added additional information. However, no participants suggested any corrections of our interpretations. 


\section{Limitations of the Study}

This study was designed to provide an understanding of the dynamics of one school's organizational restructuring into a collaborative entity conducive to the emergence of collegial practices in response to perceived professional isolation of its teachers. However, one important limitation of this study, as in all qualitative case studies, was that the selected case is not necessarily representative. The dynamics of one school are not necessarily representative of its school district, province, or schools in general. Many factors differentiate schools, such as size, the type of community served (e.g., urban or suburban), capacity, and school climate and culture. Any or all of these factors may have affected the translation of this school's collaborative organizational structure into practice in terms of the scope of its implementation and the processes used. The diversity of schools' cultures and contexts would undoubtedly lead to variation among other leaders' choices of strategies to achieve the best fit with their schools' own goals and capacities in addressing their perceived needs. Our assumption was that any school staff will respond in its own way to express its needs to change its structure (whether or not that be a collaborative organization) based on the social, organizational, cultural, and political conditions of its own context. Thus, we do not claim that this case is generalizable.

A second limitation of this study was its reliance on documents, archival records, and interviews to paint a picture of how individuals shaped, implemented, and experienced their restructured school organization. The results of this study were limited by factors of time, location, resources, and our ability as researchers to reach and gain the confidence of research participants. Although our intention was to present an accurate representation of the stories we heard and the documents we reviewed, the reality is that we were an instrument in this research and can only hope that our relationship with the research participants was such that they felt sufficiently comfortable in reviewing and criticizing our findings to ensure that they represent a reasonably accurate reflection of participants' perspectives and experiences.

\section{Findings and Discussion}

In this case study, research participants constructed and put into operational practice a specific process to transform their school into a collaborative organizational structure. They made their own specific meanings and had their own particular purposes for doing so. Their discourse was focused mainly, and almost exclusively, on establishing a collaborative school structure to confront their perceived professional isolation. They wanted to engage in professional collegial practices to address issues of teaching and educational planning. However, they stayed clear of engaging in a "discourse of possibilities" (Lavie, 2006) that would have involved "critical collaboration" (Smith, 1996) through the critique of their teaching and planning practices. We believe that this could explain the dominance of weak forms of collegial practices in this school, despite the intentional effort to create a more collaborative school organizational structure.

\section{Reasons for and Process of Organizational Change Within the School}

A feeling of professional isolation was at the forefront of the educators' life in the school. This aspect of the professional school life first came to the surface during a retreat focusing on strategic planning for the new academic year. In dealing with the issues of areas in which aspects of school life could be improved, agreement developed among educators about the general character of the school. It was perceived as a professional environment having strong norms of isolation that left all to struggle with their problems and anxieties privately, spending most time physically, socially, and intellectually apart from their colleagues. Some educators commented as follows:

We felt that teachers in our school were individuals living what I would call a quiet life of des- 
peration. Previously, we were all working in an assembly-line kind of structure. We were all so busy and overworked with the job that we had in front of us. We didn't have the time to think of professionalism. What was really good? What was really bad? You were just trying to survive. You were just trying to stand on the line and do your job, basically. (Interview - Educator D)

In spite of the fact [that] parents were extremely happy with the school, teachers were experiencing a deep sense of isolation. We should have been happy with just being part of one of the most effective and popular schools in our district, but it didn't seem to be enough for most of us. Besides socializing when we could during the day, there was no time for human contacts. Lunch time was our big social time. (Interview Educator J)

Interestingly, the issue of isolation in what seemed to be a "great" school started a cyclical inquiry process by the staff. Once they became aware of their common perception of isolation and came to an agreement, they embarked on a discussion about the implication of inquiring into the issue of isolation.

We wanted to change the nature of our relationships, our patterns of relating to one another. However, we had to come to grips with what it meant to address this issue of isolation head-on. Did we really want to do it? We were asking ourselves if we were ready to share information, decision making, work more closely together, or collaborate more intensively than before. We knew that any action would bring deep change. It was a matter of being ready to do it and assume the consequences. (Interview - Educator A).

Here, the educator is alluding to the fact that the staff were operating and interacting within an organizational structure that hindered their ability to connect and interact professionally in a collegial manner. They were looking at initiating an organizational change that purported to bring transformational changes in terms of collegiality and reduce perception of professional isolation. Furthermore, being fully aware of the generalized feeling of professional isolation, they came to the realization that the task of reducing professional isolation was beyond their individual capacities. Collective leadership and mutual trust were central to embarking on such a change process.
It takes a lot of guts and trust to take account of the views that other colleagues hold-not only about how they experience isolation but views about how a good school with a strong sense of belonging should be organized. (Interview Educator M)

We had to be transparent in our motives. We had to feel safe from retribution of any sort. We all needed to develop trust in each other. Without trust and a sense of safety, this transformation of our school would not have been possible. (Interview - Educator K)

We found three aspects that characterized this organizational restructuring process:

- Forging an initial agreement about the task at hand.

- Building leadership capacity.

- Building trust.

Staff members agreed on the purpose of the collaborative effort: to change the school's internal organizational structure as a means for coping with their feelings of professional isolation. By agreeing on the purpose for collaborating around issues of teaching and planning, they considered elements of organizational structure that would be viewed as effective in dealing with professional isolation. Building leadership capacity became central in keeping this process of collaboration going. We witnessed informal leadership develop among the educators because the process of change did not rely on clear-cut, easily enforced, centralized direction. Some educators played a leadership role as "sponsors" (they had considerable prestige, authority, and access to resources), while others played a leadership role as "champions" by focusing on keeping the collaborative effort of restructuring the school going by using their relational and political skills. As one educator indicated:

I think that pretty well everybody was committed to this project. They contributed according to their individual knowledge and ability to lead. It was quite a good example of being complementary to each other. (Interview - Educator E)

In this case, trust was the glue that held people together, as well as the lubricant that facilitated the work and kept the collaboration going. We found that trust building was an ongoing requirement in this process of restructuring the school's organization:

We trusted each other. We shared our personal expertise and ideas. There was a common bond and a sense of good will among us. 
Understanding each other's experience of professional isolation, and how to cope with it, built a solid trust in the legitimacy of the process we were going through. (Interview - Educator C)

However, absent from the change process was critical discourse (see Table 1) in which research participants might have worked to get to the core of the value commitments that underpinned the current school structure. To the contrary, participants focused much attention on the instrumental issue of professional isolation; questions of the purposes of core elements of schooling were marginalized. They saw restructuring the school organization not as a process of questioning values but as a technology for addressing perceived professional isolation by nurturing the emergence of collegial practices. They approached the issues of a collaborative school organizational structure and teacher collegiality strictly within the discourse of professional isolation. In their discourse, research participants clearly restricted their intentional restructuring to the solely to address professional isolation. As a result, we cannot report about deep transformation of the organizational structure; we can report merely about surface changes made.

\section{Emerging Patterns of Collegial Interaction Within the Restructured School Organization}

Basically, the way research participants restructured their school into what they perceived as a collaborative organizational structure mainly improved the effectiveness of the organization in facilitating the emergence of some collegial practices that responded to perceived feelings of professional isolation. The reorganization was done without disturbing or fundamentally altering basic features such as goals, structures, and roles. It is within this modified school organization that we have developed a better understanding of the organizational behaviors and actions of research participants in terms of the predominant emerging types of collegial practices.

We discovered a dichotomy between the way educators perceived their experience of the new school organization in terms of its emerging collegial interactions and the predominant forms of collegiality we observed during grade-level and general meetings. This comment made by one educator captures this common perception:

In a general way, what I like about collegiality is that it touches on the whole notion of possibilities. It allows me the opportunity or the possibility of being able to teach with my colleagues. It allows me to take chances or risks in implementing different strategies. It allows me to plan with teachers, implement with them, and talk about it [the lesson] after it has taken place. What I am trying to say is that this allows me to feel good about taking the chances that I am taking in a way that is not very threatening. I feel positive about this, even though I know I may be challenged, my values may be challenged, or the way I teach may be challenged. I think it allows that I might not feel good about it at the momentfor example, when someone questions me and says, "This is not really effective or the way it should be" or "How about trying it this way?" (Interview - Educator A)

Other participants indicated that collegial interactions should not be limited to anecdotes, giving aid only when asked, or pooling existing ideas:

I think that we need to confront each other's values and ways of understanding what good teaching is. I didn't have many chances to do so, but I think we should look into having more working sessions like that. (Interview Educator F)

Sometimes, I would like to create new projects, new material for students. Up to now, several of us have pooled our teaching ideas and materials together and put them in files to be shared with others. (Interview - Educator J)

However, what we observed during grade-level meetings and general school meetings painted a different picture. In their actual interactions, we found that participants kept critical analysis of one another's practices, as well as the tougher questions about their work and how to improve it, completely off the agenda.

How can we increase the literacy rate at the end of the primary years (grades 1 to 3 )? This is an issue that is central to today's meeting. Teachers are looking at ways that could help to increase the level of literacy (reading and writing) in both French and English. They focus on the time allotment in the schedule for the teaching of reading and writing. The problem is treated as a question of time and scheduling, not in terms of teaching practices. The latter is kept off the agenda. One educator suggests that they should consider implementing guided reading across grades. This suggestion leads the discussion toward the meaning of teaching reading. They are conflicting with each other as some educators express the view that such a decision is up to each individual. They decide to allocate money to build up collections of graded reading books to be used by educators in their own classrooms. The chance of discussing alternative 
ways of understanding reading learning processes and trying cutting-edge new ways of doing things is of no avail (Excerpt from field notes - grade-level meeting November 2002).

The evidence codified in our field notes and corroborated by research participants shows that the reorganized school structures primarily facilitated the emergence of these forms of collegial interactions: lending and borrowing material; brainstorming; preparing lesson plans; praising other teachers and offering reassurance; giving advice to others, when asked; and sharing concerns, problems, and criticisms of the school.

Our findings indicate that the forms of collegiality experienced by the participants were limited to pooling existing ideas, scanning for specific ideas, asking for aid and assistance, and sharing ideas and materials without submitting them to critical analysis or extending them. Participants emphasized reassurance and sympathy while discouraging close scrutiny and criticism:

I don't think that we really bargained for having our stuff questioned and changed by other colleagues. We wanted to function as a collegial group, but for most of us, it didn't mean much more than supporting each other in what we have been doing up to now. For myself, it is important to be with others, work with them, and cry with them sometimes, but there are boundaries that I like to maintain and stuff that I like to keep private and out of sight. It doesn't mean that I won't be ready one day to ask some of my colleagues their opinion and judgment about what I am doing, but now, I like the way things are right now. I feel like I belong and that is important for me, and I don't want conflicts to ruin that. (Interview - Educator P)

These findings corroborate the literature on the dominance of comfortable kinds of collegiality in schools, even those with structural arrangements designed to facilitate individual and uncontrived and agreed-upon professional collegial practices (Barth, 1990; Fullan, 1991, 2007; Little, 1990). These kinds of collegial practices restrict the extent to which teachers can inquire into and advise one another about their practice, because they keep at bay the tougher questions about their work and how to improve it.

In our study, the dominance of comfortable kinds of collegiality suggests that there were limits on the degree of professional isolation that participants actually wanted to overcome through the reorganization of their school:

I am not comfortable to make comments on teaching practices of colleagues. It would sound like I was making a judgment on their professionalism. I would not like to have my ways of doing things to be judged by others, unless I asked for it. If we are going to maintain trust among ourselves, we need to keep dissension to a minimum. (Interview - Educator A)

What we have deduced from our data is more a shifting of the boundaries that maintain some isolation or professional privacy rather than a total dismantling of them. This result could be explained partly by the fact that schools are pluralistic entities teeming with differences, and the individual educators within them have the need to maintain a certain degree of self-determination over their professional work. Our study has shown that for the educators involved in the study, redesigning a school's organizational structure for the purpose of fostering collegiality (to overcome feelings of isolation) has come to signify one way of accommodating those professional needs for collaborative relationships. At the same time, such relationships protect the group's professional diversity by allowing individuals to maintain professional boundaries around their work. In this sense, our study shows that a collaborative organizational school structure inhabited by a plurality of singular professional beings may never lead to a total unity of experience or perspective within a staff. In our study, the drive to create collective frames of connection through collegial practices among educators appeared to be always shifting, remaining porous and malleable as a way to manage differences within the school.

None of our collected data spoke directly to the reasons underlying these forms of collegial relationships. However, we can derive from our evidence that these educators-besides not wanting to be perceived as critical of others' work, or being aggressive or inquisitive, and not wanting to be perceived as difficult to get along with-wanted to maintain their boundaries and their degree of independence and self-determination from the collective and from one another. We hold the view that the dominance of comfortable forms of collegiality we saw and the resulting degree of privacy (or isolation) between educators was the product of a tacit agreement secured between them. Furthermore, our analysis reinforces the argument that, in this case study, teacher-initiated organizational restructuring of the school was not a process of questioning values and examining alternative visions of schooling; rather, it was a technology for improving professional relationships within conventional definitions of schooling. This would explain the dominance of weak forms of collegial practices as the main result of the school restructuring. In our study, research 
participants adopted a collaborative discourse that called for a certain degree of professional interdependence and collegial practices while retaining space for individual autonomy and discretionary professional judgment.

\section{Implications of This Case Study}

The body of data from this study is not sufficient to formulate significant and applicable recommendations regarding the initiation and sustainability of deeper kinds of collegiality for teachers and administrators through the transformation of a school's organizational structure into a collaborative one. However, our study highlights the importance of examining not only the structural change a school may make but also the process by which the transformation took place, including underlying values and principles (such as the one we observed in this study), In fact, transforming a school's organizational structure into a collaborative one is a value-oriented practice (Lavié, 2006), which means that any such restructuring is a political endeavor requiring a thorough questioning of the rationale underlying it. In terms of leadership practice and educational change, this case study demonstrates the need to attend to the different ways of understanding the notion of a collaborative workplace and the connection to the types of collegial practices that can be sustained on a long-term basis. That is, although shaping the school as a collaborative workplace as a way to address professional isolation raises the issue of "how to," this case study poses a more fundamental question of "what for". This question was not part of the change process undertaken by the research participants. Instead, their restructuring initiative and the resulting kinds of collegial practices appear to have been framed by a particular certain focus, meaning of collaborative workplace, and a value orientation underpinned by a strictly instrumental rationality; any critique of the content and purposes of school fell outside these parameters.

Further research is needed to focus on discerning and elucidating useful insights into better ways to facilitate and sustain more profound kinds of collegial practices in schools. While the literature is rich in conclusions dealing with the "why" and "how" of the dominance of "comfortable" collegiality, it remains short on hard data explaining why and how a school can initiate, nurture, and successfully sustain educationally significant kinds of collegiality, as well as identifiable transformations of teaching realities and practices. Our conceptual framework would prove useful in identifying and investigating schools where more substantive kinds of collegiality exist among teachers. It could also demonstrate the ways that some schools can be successful in creating visible transformations of both their own thinking and their teaching realities and practices while defining the social, cultural, and organizational conditions that facilitate the emergence of deeper kinds of collegiality.

Further investigation of school conditions conducive to deeper collegiality would lead scholars and field-based practitioners to realize that not all discourse underlying the construct of a collaborative workplace and collegial practices aspires to transform teaching, learning, and professional relationships. Some conditions would likely reinforce existing practices and values, marginalizing questions of purposes and values while emphasizing instrumental issues of schooling and interactions among educators. Like the Lavié research (2006), our case study led us to argue that future research dealing with the emergence and sustainability of deeper kinds of collegial practices should be conducted according to "a discursive reading of approaches to teacher collaboration involving different visions of schooling and resulting from a different value commitment" (Lavié, 2006, p. 796). As Lavié highlighted in his work, we believe that approaching the practice of collaboration in a school setting and collegial practices from "one discourse or another ultimately depends on the vision of schooling we are committed to and the type of changes we wish to bring about" (p.796).

\section{Conclusion}

Our research departs from the notion that the transformation of an organizational structure into a deeper collaborative and collegial school setting will necessarily lead to a significant dissipation of teachers' perception of isolation. In this study, the transformation of organizational structure of the school elicited and molded, to an extent, the professional behaviors of staff members into professional collegial patterns of interactions. However, despite the fact that the desire for uncontrived collegiality was mainly the result of a collective effort to address the issue of professional isolation, educators seemed to have made individual choices to maintain a certain degree of isolation, of privacy, shielding themselves from reflective inquiry and criticism. Their motivation for engaging in such a restructuring effort was instrumental in nature (reducing professional isolation); it was based not on critical reflection of educators' teaching practices but on building support and maintaining harmony. The educators maintained their boundaries around some of their professional activities in order to accommodate and 
minimize tensions, conflicts, and opposition among themselves. Our evidence demonstrates that restructuring a school organizationally into a collegial setting as a process of coping with isolation might end up in shifting rather than dismantling boundaries of isolation among educators. Our evidence aligns with findings by other researchers that, given the autonomy that is inherent to their profession and the discretion in emergent organizational structures fostering collegial practices in coping with isolation, educators make individual choices regarding the extent to which they want to engage in collegial professional interactions on the basis of individual considerations. (Bakkenes, De Brabander, \& Imants, 1999; Imants \& Bakkenes, 1993).

\section{References}

Bakkenes, I., De Brabander, C., \& Imants, J. (1999). Teacher isolation and communication network analysis. Educational Administration Quarterly, 35(2), 166-202.

Barth, R. S. (1990). Improving schools from within. San Francisco: Jossey-Bass.

Brint, S. (2001). Gemeinschaft revisited: A critique and reconstruction of the community concept. Sociological Theory, 19(1), 1-23.

Campbell, P., \& Southworth, G. (1992). Rethinking collegiality: Teachers' views. In N. Bennett, $\mathrm{M}$. Crawford, \& C. Riches (Eds.), Managing change in education: Individual and organizational perspective (pp. 31-42). London: Paul Chapman Publishing.

Creswell, J. W. (1998). Qualitative inquiry and research design: Choosing among five traditions. Thousand Oaks, CA: Sage Publications.

Deaudelin, C., Dussault, M., \& Thibodeau, S. (2003). Les cause de l'isolement des enseignantes et des enseignants. McGill Journal of Education, 38(1), 49-51.

Denzin, N. K., \& Lincoln, Y. S. (2000). Introduction: The discipline and practice of qualitative research. In N. K. Denzin \& Y. S. Lincoln (Eds.), The handbook of qualitative research, 2nd ed. (pp. 3-28). Thousand Oaks, CA: Sage Publications.

Flinder, D. J. (1988). Teacher isolation and the new reform. Journal of Curriculum and Supervision, 4(1), 17-29.

Fullan, M. G. (1991). The new meaning of educational change. New York: Teachers College Press.

Fullan, M. G. (1993). Change forces. London: Falmer Press.
Fullan, M. G. (2007). Change the terms for teacher learning. Journal of Staff Development, 28(3), 3541.

Fullan, M. G., \& Hargreaves, A. (1992). What is worth fighting for? Working together for your school. Toronto, ON: Ontario Teachers' Federation.

Glaser, B. G. (1967). The discovery of grounded theory: Strategies for qualitative research. New York: Aldine.

Graham, K. C. (2001). Promoting collegial relationships between physical educators and other faculty. Journal of Physical Education, 72(5), 52-55.

Grimmett, P. (2000). Breaking the mold. In T. D. Carson \& D. Sumara (Eds.), Action research as living practice (pp. 121-136). New York: Lang.

Hoy, W., \& Sweetland, S. (2001). Designing better schools: The meaning and measure of enabling school structures. Educational Administration Quarterly, 37(3), 296-321.

Imants, J., \& Bakkenes, I. (1993). Professional isolation of teachers, school culture, and teachers' sense of efficacy. In F. Kievet \& R. Vandenberghe (Eds.), School culture, school improvement, and teacher development (pp.171-197). Leiden, NL: DSWO Press.

Irwin, J. W., \& Farr, W. (2004). Collaborative school communities that support teaching and learning. Reading and Writing Quarterly, 20, 343-363.

Jarzabkowski, L. M. (2002). The social dimensions of teacher collegiality. Journal of Educational Enquiry, 3(2), 1-20.

Johnson, B. L. (1998). Organizing for collaboration: A reconsideration of some basic organizing principles. In D. G. Pounder (Ed.), Restructuring schools for collaboration: Promise and pitfalls (pp. 9-25). Albany, NY: State University of New York Press.

Lavié, J. M. (2006). Academic discourses on schoolbased teacher collaboration: Revisiting the arguments. Educational Administration Quarterly, 42(5), 773-805.

Levy, A., \& Merry, U. (1986). Organizational transformation: Approaches, strategies, theories. New York: Preager.

Lincoln, Y. S., \& Guba, E. G. (1985). Naturalistic inquiry. Newbury Park, CA: Sage Publications.

Little, J. W. (1982). Norms of collegiality and experimentation: Workplace conditions of school success. American Educational Research Journal, 19, 325340. 
Little, J. W. (1990). The persistence of privacy: Autonomy and initiative in teachers' professional relations. Teacher College Record, 91(4), 509-534.

Lortie, D. C. (1975). Schoolteacher: A sociological study. Chicago: University of Chicago Press.

Marks, H., \& Louis, K. (1999). Teacher empowerment and the capacity for organizational learning. Educational Administration Quarterly, 35, 707-750.

Matuzov, E., \& Hayes, R. (2002). Building a community of educators versus effecting conceptual change in individual students: Multicultural education for pre-service teachers. In G. Wells \& G. Claxton (Eds.), Learning for life in the 21st century: Sociocultural perspectives on the future of education (pp. 239-251). Oxford, UK: Blackwell.

McMillan, D. W. (1996). Sense of community. Journal of Community Psychology, 24(4), 315-325.

Miles, M. B., \& Huberman, A. M. (1994). An expanded sourcebook: Qualitative data analysis (2nd ed.). Thousand Oaks, CA: Sage Publications.

Mirriam, S. B. (1998). Qualitative research and case study applications in education. San Francisco: Jossey-Bass.

Robson, C. R. (1993). Real world research: A resource for social scientists and practitioner-researchers. Oxford: Blackwell.

Rosenholtz, S. (1989). Teachers' workplace: The social organization of school. New York: Longman.

Sergiovanni, T. J. (1990). Value-added leadership: How to get extraordinary performance in schools. San Diego, CA: Harcourt Brace Jovanovich.
Smith, B. (1996). What did we mean when we argued for "critical collaborative communities"? In J. Smyth (Comp.), Schools as critical collaborative communities. Adelaide, Australia: The Flinders Institute for the Study of Teaching.

Smith, S. C., \& Scott, J. J. (1990). The collaborative school: A work environment for effective instruction. Eugene, OR: ERIC Clearinghouse on Educational Management and the National Association of Secondary School Principals.

Tschannen-Moran, M., Uline, C., Woolfolk Hoy, A., \& Mackley, T. (2000). Creating smarter schools through collaboration. Journal of Educational Administration, 38(3), 247-272.

Vygotsky, L. S. (1978). Mind in society: The development of higher psychological processes (M. Cole, Ed.). Cambridge, MA: Harvard University Press.

Welch, R., \& Panelli, R. (2007). Questioning community as a collective antidote to fear: Jean-Luc Nancy's "singularity" and "being singular plural." Area, 39(3), 349-356.

Yin, R. K. (2003). Applications of case study research. Thousand Oaks, CA: Sage Publications.

Zellermayer, M. (2001). Resistance as catalyst in teachers' professional development. In C. M. Clark (Ed.), Talking shop: Authentic conversation and teacher leaning (pp. 40-63). New York: Teachers College Press.

Zellermayer, M., \& Margolin, I. (2005). Teacher educa tors' professional learning described through the lens of complexity theory. Teacher College Record, 107(6), 1275-1304. 